Cite this: J. Mater. Chem. B, 2014, 2, 3915

\title{
Biocompatible, hyperbranched nanocarriers for the transport and release of copper ions $\dagger$
}

Received 21st March 2014

Accepted 16th April 2014

DOI: $10.1039 / c 4 t b 00454 j$

www.rsc.org/MaterialsB

Core-shell and core-multishell nanocarriers were designed to transport copper ions into cells. Herein, we present their synthesis and physicochemical characterization and demonstrate the high influence of their architectures on the loading and release of copper. Their low toxicity may open a new way to balance the $\mathrm{Cu}$-homeostasis in neurodegenerative diseases.

Copper $(\mathrm{Cu})$ is an important biological cofactor for a number of metalloenzymes and plays a key role in many neurodegenerative diseases, ${ }^{1}$ e.g., Alzheimer's disease (AD) and Parkinson's disease. Particularly in the case of AD, disturbed homeostasis of $\mathrm{Cu}$ leads to $\mathrm{Cu}$ deficiency in the central nervous system (CNS). Exogenous supply of $\mathrm{Cu}$ to the brain or CNS is one of the many therapeutic approaches for addressing such deficiency symptoms. ${ }^{2}$ For such a purpose, copper supply needs to bypass the blood-brain barrier (BBB), which remains an unsolved problem. Additionally, hyperperfusion in the AD brain leads to decreased $\mathrm{pH}$ and inflammatory processes in the CNS. ${ }^{3}$ All the previous information helps in the design of smart nanocarriers capable of performing $\mathrm{Cu}$ pH-triggered delivery across the BBB (see Scheme 1). Hyperbranched polymers are promising representatives of size controllable nanoscaffolds for transport and drug delivery. ${ }^{4-7}$ In previous studies, hyperbranched poly(ethyleneimine) (PEI) has been used to develop Cu-encapsulating nanocarriers. ${ }^{8}$ However, the poor biocompatibility due to the presence of a large number of amine groups within PEI limits the applications of such systems.

${ }^{a}$ Institut für Chemie und Biochemie, Organische Chemie, Freie Universität Berlin, Takustr. 3, 14195 Berlin, Germany.E-mail: haag@chemie.fu-berlin.de

${ }^{b}$ Laboratoire des Interactions Moléculaires et Réactivités Chimiques et Photochimiques, Université de Toulouse, CNRS UMR 5623, 31062 Toulouse Cedex 09, France

${ }^{c}$ Department of Pharmacology and Therapeutics, McGill University, 3655 Promenade Sir-William-Osler, Montréal, QC H3G 1Y6, Canada

$\dagger$ Electronic supplementary information (ESI) available: Experimental section, $\mathrm{Cu}$ and $\mathrm{Zn}$ loading capacity, pH-triggered Cu release, colloidal behavior in water, and metal ion competition. See DOI: 10.1039/c4tb00454j
To enhance biocompatibility, new core-multishell nanocarriers with lower toxicity are required, e.g., functionalized, hyperbranched polyglycerol (hPG). As a macromolecule, hPG possesses a highly branched, globular dendritic structure of a stable polyether scaffold and can be synthesized in a one-step process. ${ }^{9}$ It exhibits similar properties to the well-used and FDAapproved poly(ethylene glycol) (PEG), as it is non-toxic, biocompatible, and not recognized by the immune system. ${ }^{10}$ Furthermore, modification of hPG is facile due to its large number of peripheral hydroxyl groups. These functionalized hPG can therefore be tailored to required properties such as size, charge, or molecular weight, respectively.,11-15 By the attachment of shells, specialized architectures can be designed for a wide variety of applications. ${ }^{16-20}$

Herein, we present the synthesis and properties of different modified hPG to develop biocompatible Cu-nanocarriers as potential candidates in the therapy of $\mathrm{Cu}$ deficiency disorders. An hPG with a molecular weight of $10 \mathrm{kDa}$ was selected for the core in order to obtain nanocarriers of a few tens of nanometers. Cu-binding ligands to be attached on hPG cores were then reviewed to fit in our specifications. An example of Cu-binding ligands are triazacyclononanes, which are known to form very strong complexes with $\mathrm{Cu}$ that are irreversible under physiological conditions. ${ }^{21}$ Clearly, copper-release into CNS acidic conditions requires a weaker ligand for a $\mathrm{pH}$-triggered release of $\mathrm{Cu}$. Tri- or dimethylethylene diamine moieties (TMEDA or DMEDA, respectively) have been chosen as suitable candidates. ${ }^{22}$ They form square planar bidentate $\mathrm{Cu}$-complexes with

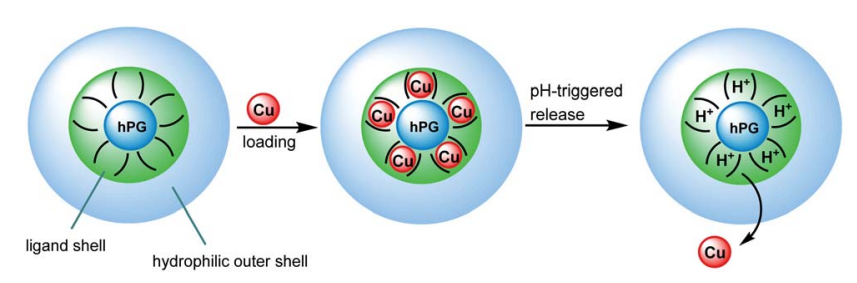

Scheme 1 Encapsulation and release of $\mathrm{Cu}$ ions in nanocarrier systems. 
moderate interactions, which enable $\mathrm{pH}$-dependent $\mathrm{Cu}$ release. Furthermore, in order to increase the biocompatibility, to enhance the retention time within blood circulation, or to hide $\mathrm{Cu}$ from the environment, attachment of poly(ethylene glycol) (PEG) chains in the outer sphere is required (see Scheme 1). Two kinds of attachments were chosen to investigate the influence of structural design of nanocarriers on Cu-loading and release, as well as their biocompatibility. Thus, hydrophilic PEG chains were bound to amine building blocks leading to a core-multishell structure (CMS) or directly to the hPG core for a corerandom shell architecture (CRS) (see Scheme 2). Finally, hPG fully modified by TMEDA (CS structure in Scheme 2) was used as a reference system. ${ }^{23}$

For the CMS synthesis, boc-protected DMEDA was first reacted with hPG to cover 70\% of the hydroxyl groups of hPG's surface. After deprotection, $\mathrm{PEG}_{1000}-\mathrm{OM}$ chains were attached to the amino ligands. For the CRS, reaction of hPG with TMEDA was controlled to yield a degree of functionalization on hPG's surface of $70 \%$ (similar to that of CMS). The remaining mesylates were then substituted by azides, which could be used in a click reaction to attach propargylated $\mathrm{PEG}_{5000}$ (see characterization of CMS and CRS in the ESI $\uparrow$ ).

UV/vis spectroscopic experiments were then carried out to determine the maximum Cu-loading capacity of the nanocarrier in water. A stock solution of the polymer was mixed with an increasing amount of $\mathrm{Cu}(\mathrm{II})$ to achieve different $\mathrm{Cu}$ : polymer molar ratios. Regardless of the polymer structure, an increase of the absorbance at $580 \mathrm{~nm}$ was observed and should be related to the $\mathrm{d}-\mathrm{d}$ transition of copper ions complexed by amine functions (see Fig. S1 in the ESI $\uparrow$ ). This demonstrated the complexation of $\mathrm{Cu}$ inside the nanocarriers. Above a certain concentration of copper, the absorbance at $580 \mathrm{~nm}$ became constant and a new band around $800 \mathrm{~nm}$ related to aqueous copper ions grew in size. This behavior is evidence for the saturation of nanocarriers and that the later added copper ions remained free in solution. The plot of the absorbance at $580 \mathrm{~nm}$ for the increasing $\mathrm{Cu}$ : polymer ratio reveals that the CMS

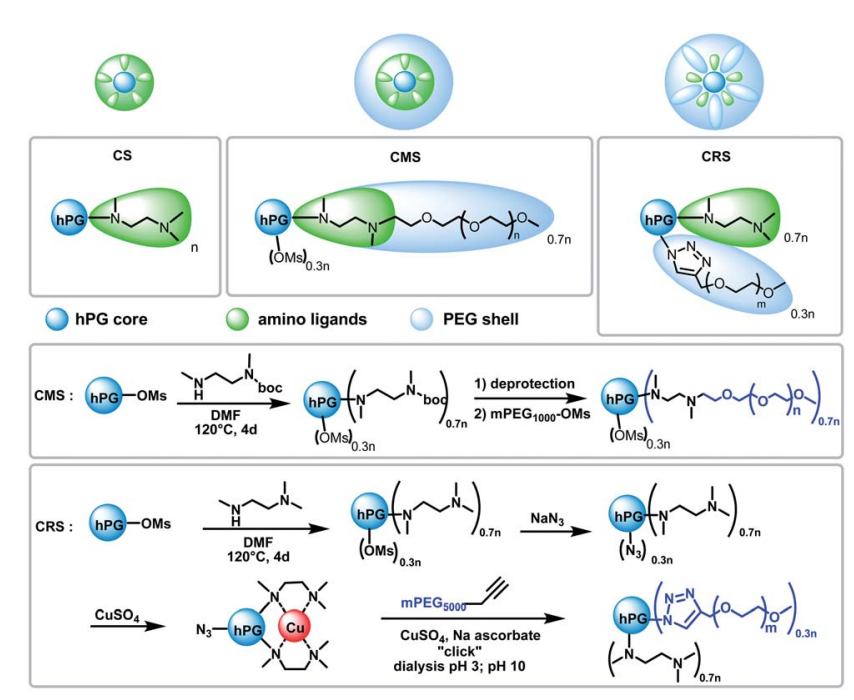

Scheme 2 Structure and synthesis scheme of CS, CMS and CRS. structure can load more copper ions than the CRS polymer (see Fig. 1a). The close fit of these curves (see ESI $\dagger$ ) leads to a more quantitative evaluation of this maximum loading (see Table 1).

To check the loading capacity, we developed a second method based on centrifugal filtration of the metal ion/polymer solution. Titration of the metal ion was performed on the filtrate using a well known spectroscopic method based on the Zincon indicator (see Fig. S2 in the ESI†). ${ }^{24}$ As seen in Fig. 1b, the CS system retains copper ions until a maximum loading of approx. 30 . This is quite comparable with the direct evaluation by UV/vis spectroscopy. Assuming a binding site of two ligands per copper, one can estimate the maximum theoretical number of sites per polymer and therefore the percentage of active sites. As seen in Table 1, similar values were found for CS and CMS structures. In contrast, the architecture of the CRS polymer is less favorable for complexing $\mathrm{Cu}$ metal ions, which may be due
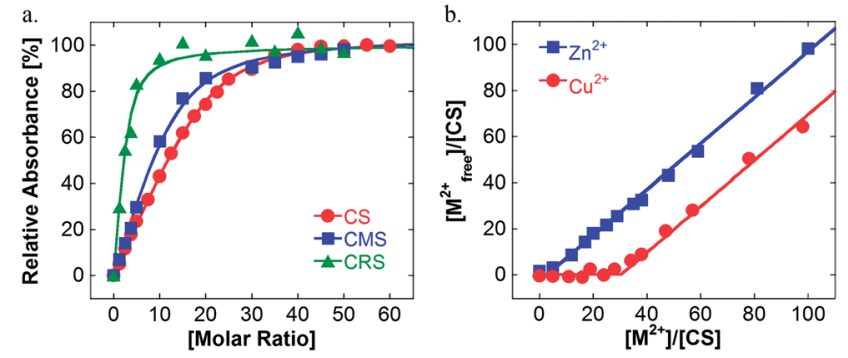

Fig. 1 Determination of the maximum loading of polymers by UVvisible measurements. (a) Influence of the $\mathrm{Cu}$ : nanocarrier molar ratio on the relative absorbance at $580 \mathrm{~nm}$ at room temperature with a constant polymer concentration $(80 \mu \mathrm{M})$. (b) Free metal ion concentration depending on metal: CS molar ratios at room temperature with CS concentration $(6.2 \mu \mathrm{M})$.

Table 1 Properties of the CS, CMS and CRS structures

\begin{tabular}{|c|c|c|c|}
\hline & CS & CMS & CRS \\
\hline Loading capacity $^{a}$ & $22 \pm 4$ & $14 \pm 3$ & $5 \pm 2$ \\
\hline $\begin{array}{l}\text { Percentage of } \\
\text { active sites }^{b}\end{array}$ & $46 \pm 9 \%$ & $42 \pm 9 \%$ & $15 \pm 6 \%$ \\
\hline $\begin{array}{l}\text { Relative intake } \\
\text { kinetics }^{c}\end{array}$ & 1 & 11 & 36 \\
\hline $\operatorname{Size}^{d}(\mathrm{~nm})$ & $12 / 8$ & $8 / 5$ & $360^{e} / 6$ \\
\hline $\begin{array}{l}\mathrm{pH} \text { for } 10 \% \text { of } \\
\text { copper release }\end{array}$ & 4 & 4 & 7 \\
\hline $\begin{array}{l}\text { Relative pH-release } \\
\text { kinetics }^{c}\end{array}$ & 1 & 2 & 3 \\
\hline $\begin{array}{l}\text { Cytotoxicity of the } \\
\text { polymer }\end{array}$ & $\begin{array}{l}38.1 \mathrm{mg} \mathrm{Cu} \\
\text { per } \mathrm{L}\end{array}$ & $\begin{array}{l}4.8 \mathrm{mg} \mathrm{Cu} \\
\text { per } \mathrm{L}\end{array}$ & $\begin{array}{l}4.1 \mathrm{mg} \mathrm{Cu} \\
\text { per } \mathrm{L}\end{array}$ \\
\hline $\begin{array}{l}\text { loaded with } \\
\text { copper }\left(\mathrm{IC}_{50}\right)^{f}\end{array}$ & $\begin{array}{l}220 \mathrm{mg} \mathrm{CS} \\
\text { per L }\end{array}$ & $\begin{array}{l}415 \text { mg CMS } \\
\text { per L }\end{array}$ & $\begin{array}{l}2.9 \mathrm{~g} \text { CRS } \\
\text { per L }\end{array}$ \\
\hline
\end{tabular}

${ }^{a}$ Determined by UV-visible spectroscopy (see text). ${ }^{b}$ Ratio between the experimental loading capacity and the maximum theoretical number of sites per polymer estimated as half the number of ligand ethylene diamine per polymer. ${ }^{c}$ Determined by UV-visible spectroscopy (see ESI). ${ }^{d}$ Hydrodynamic radius (nanocarriers/Cu-loaded nanocarriers) determined by DLS with an analysis in number from $80 \mu \mathrm{M}$ nanocarrier solutions. ${ }^{e}$ Aggregation. ${ }^{f}$ Determined on human neuroblastoma cell line SH-SY5Y. 
to the higher steric hindrance from the PEG-chains attached between TMEDA-ligand units as well as from the aggregation of CRS. The binding kinetics were fast and equilibrium was reached only after a few minutes (see Fig. S1 in the ESI $\dagger$ ). All these results indicated a behavior highly related to the architecture of the nanocarrier.

After addition of copper ions into a polymer solution, reaching the equilibrium was a slower process for CRS than CMS or CS (see Table 1). This may be partially due to the PEG layer (larger in CRS than in CMS), which should have decreased the accessibility of ions toward the ligand shell.

The ability for such structures to interact with other ions may be providential for the delivery of copper in a controlled manner. To evaluate such a possibility, a large excess of different ions (Ca, Mg, Mn, Co, Zn, Ni) was added to $\mathrm{Cu}$-loaded nanocarrier solutions (see Fig. S6 in the ESI $\dagger$ ). None of the metal ions were able to displace copper ions from the hyperbranched structures.

Moreover, no direct complexation could be evidenced for zinc ions, another ion of interest in the case of $\mathrm{AD},{ }^{25}$ as shown in Fig. 1b. Thus, the obtained nanocarriers were of special interest for the specific complexation and delivery of copper.

Blood clearance for molecules below $60 \mathrm{kDa}$ and $6 \mathrm{~nm}$ is fast, while bigger particles remain longer in the blood. ${ }^{26,27}$ However, particles bigger than $200 \mathrm{~nm}$ are likely renally excreted. ${ }^{28}$ Since size also has a big impact on the permeability of the BBB of substances, ${ }^{29-31}$ the size of the empty and $\mathrm{Cu}$-loaded nanocarriers was investigated by dynamic light scattering (see Fig. S4 in the ESI $\dagger$ ). Empty nanocarriers in solution as a unimer were found to have a hydrodynamic diameter close to $10 \mathrm{~nm}$ (see Table 1). When CMS was only in the form of unimer, CS and CRS nanocarriers were more or less present as polydisperse aggregates in solutions $\left(R_{\mathrm{h}}\right.$ above $100 \mathrm{~nm}$ ). When $\mathrm{Cu}$ was stabilized inside nanocarriers, a significant decrease of the aggregation and a slight change in the size of the unimer were observed. Thus, the nanocarriers presented here having molecular weights above $80 \mathrm{kDa}$ and diameters $d \geq 8 \mathrm{~nm}$ are in the right range for application as a delivery system. However, permeation through the BBB might be critical, since it has been postulated that most molecules bigger than $400 \mathrm{Da}$ are not able to pass the BBB. ${ }^{29}$ On the other hand, it was observed that the ability to cross the BBB is much higher for NPs with cationic character..$^{30-32}$ Due to this, zeta potentials of empty and $\mathrm{Cu}$-loaded nanocarriers were studied at $\mathrm{pH}$ values ranging from 7 to 3 in buffer solution. At $\mathrm{pH} 7$, the zeta potential of empty CS was found to be $30 \pm 9 \mathrm{mV}$. As expected, grafting of PEG chains induced a significant decrease of zeta potential that remained slightly positive for both CRS (+13.9 $\pm 0.8 \mathrm{mV})$ and CMS (+9.2 $\pm 1.0 \mathrm{mV})$ (see Fig. S5 in the ESI $\dagger$ ). Partial protonation of amine groups may have been responsible for this observation. Therefore, the highest zeta potentials were measured at $\mathrm{pH} 3$ due to the increase of the protonation level at lower $\mathrm{pH}$. Interestingly, the surface charge at all the $\mathrm{pH}$ values did not significantly evolve when $\mathrm{Cu}$ ions were stabilized inside the nanocarriers. Therefore, these positively charged nanocarriers have high potential to cross the BBB.
To prove whether nanocarriers were able to release copper ions at low $\mathrm{pH}, \mathrm{UV} / \mathrm{vis}$ spectroscopy experiments were performed. $\mathrm{Cu}$-loaded nanocarriers were transferred in Britton Robinson universal buffer aliquots with $\mathrm{pH}$ values from 8 to 2 and the absorbance was monitored (see Fig. S3 in the ESI $\dagger$ ). Fig. 2 shows the percentage of Cu-release as a function of $\mathrm{pH}$. As a result, Fig. 2 shows that CRS nanocarriers continuously released $\mathrm{Cu}$ with decreasing $\mathrm{pH}$. This profile of release highlights the weakness of these nanocarriers due to the random architecture as discussed above and might be too prompt, since the release already started at $\mathrm{pH}$ 7. For application in biological systems a controlled release is therefore not possible presumably due to $\mathrm{Cu}$ leakage before the required target was reached. On the other hand, Cu-complexes' integrity was retained in CS and CMS structures until lower $\mathrm{pH}$ values. This indicates a stronger $\mathrm{Cu}$ binding in this architecture which makes it a good candidate for carrying its entire load to the target, after which a sharp and fast $\mathrm{Cu}$ release could occur according to Fig. 2 and kinetics data (see Fig. S3 in the ESI†).

The toxicity of Cu-loaded and empty nanocarriers in human neuroblastoma (SH-SY5Y) cells was then investigated by MTT assay (see experimental procedures in the ESI $\dagger$ ). The $\mathrm{IC}_{50}$ value of CRS was found to be $22.4 \mathrm{~g} \mathrm{~L}^{-1}$, which was much higher and therefore less toxic than CMS ( $\left.\mathrm{IC}_{50} c a .415 \mathrm{mg} \mathrm{L}{ }^{-1}\right)$. It is known that long PEG-chains lead to higher biocompatibility. ${ }^{33}$ Hence, we assume that CRS with longer MPEG-chains shows less toxicity than CMS, i.e., shielding of the amino ligands by mPEGchains determines the toxicity of the cargo in living cells. Both nanocarriers in the present study were less toxic than the previously described PEI-based $\mathrm{CMS}^{8}$ which supported our earlier assumption that the hPG-based nanocarrier has a higher compatibility than nanocarriers with a PEI core. Investigation on the toxicity of Cu-loaded nanocarriers showed the same result for CMS as for empty particles regarding the nanocarrier concentration $\left(\mathrm{IC}_{50}[\mathrm{Cu}: \mathrm{CMS}=15: 1]=415 \mathrm{mg} \mathrm{L}^{-1}\right)$. In contrast, the cytotoxicity of $\mathrm{Cu}$-loaded CRS increased to $\mathrm{IC}_{50}$ $[\mathrm{Cu}: \mathrm{CRS}=5: 1]=2.9 \mathrm{~g} \mathrm{~L}^{-1}$ in comparison to unloaded CRS. Regarding the $\mathrm{Cu}$ concentration, however, Cu-loaded CMS was in the same range as $\mathrm{Cu}$ : CRS in terms of cytotoxicity (see Table 1). Both nanocarriers could reduce the toxicity of $\mathrm{Cu}$ by a factor of $7 .^{8}$ The compatibility at high loading is especially of importance for in vivo applications when a high local concentration of $\mathrm{Cu}$ is required. According to these results, it seems that CMS is a better candidate for the treatment of $\mathrm{Cu}$ deficiency disorders.

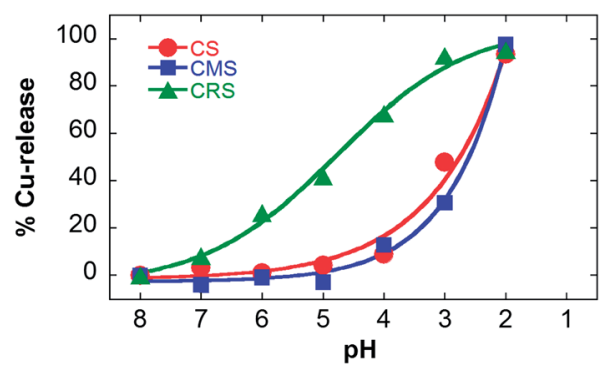

Fig. $2 \%$ Cu-release based on the relative absorbance at $580 \mathrm{~nm}$ of the CMS or CRS polymer $(80 \mu \mathrm{M})$ in Britton Robinson Buffers, $0.1 \mathrm{M} \mathrm{NaCl}$ at $37^{\circ} \mathrm{C}$. 


\section{Conclusions}

By designing new core-shell polymeric structures, we were able to obtain nanocarriers that had a high binding affinity for copper ions and were able to release these ions at low $\mathrm{pH}$. We demonstrate that the exact architecture of the core-shell system is a paramount parameter to control the maximum loading, the strength of complexation, and the release profile of copper into the solution. The CMS structure proved to be the most promising structure for $\mathrm{Cu}$ complexation and release. The CMS structure will be studied to estimate its transport through the BBB and tested in vivo for the release of copper.

\section{Acknowledgements}

This work was financially supported by the ANR-DFG program (ANR-11-INTB-1004, "Dendrion-Bio"). The authors would like to thank the SFB 1112 and the Helmholtz portfolio project "Technologie und Medizin" for financial support and Christina Kühl for technical assistance.

\section{Notes and references}

1 M. A. Telpoukhovskaia and C. Orvig, Chem. Soc. Rev., 2013, 42, 1836-1846.

2 D. J. Waggoner, T. B. Bartnikas and J. D. Gitlin, Neurobiol. Dis., 1999, 6, 221-230.

3 G. J. Broussard, J. Mytar, R. C. Li and G. J. Klapstein, Inflammopharmacology, 2012, 20, 109-126.

4 M. Calderón, M. A. Quadir, S. K. Sharma and R. Haag, Adv. Mater., 2010, 22, 190-218.

5 M. A. Quadir and R. Haag, J. Controlled Release, 2012, 161, 484-495.

6 F. Aulenta, W. Hayes and S. Rannard, Eur. Polym. J., 2003, 39, 1741-1771.

7 M. Krämer, J. F. Stumbe, H. Turk, S. Krause, A. Komp, L. Delineau, S. Prokhorova, H. Kautz and R. Haag, Angew. Chem., Int. Ed., 2002, 41, 4252-4256.

8 C. Treiber, M. A. Quadir, P. Voigt, M. Radowski, S. J. Xu, L. M. Munter, T. A. Bayer, M. Schaefer, R. Haag and G. Multhaup, Biochemistry, 2009, 48, 4273-4284.

9 D. Wilms, S.-E. Stiriba and H. Frey, Acc. Chem. Res., 2009, 43, 129-141.

10 R. K. Kainthan, J. Janzen, E. Levin, D. V. Devine and D. E. Brooks, Biomacromolecules, 2006, 7, 703-709.

11 D. Gröger, F. Paulus, K. Licha, P. Welker, M. Weinhart, C. Holzhausen, L. Mundhenk, A. D. Gruber, U. Abram and R. Haag, Bioconjugate Chem., 2013, 24, 1507-1514.
12 S. Reichert, P. Welker, M. Calderon, J. Khandare, D. Mangoldt, K. Licha, R. K. Kainthan, D. E. Brooks and R. Haag, Small, 2011, 7, 820-829.

13 D. Steinhilber, S. Seiffert, J. A. Heyman, F. Paulus, D. A. Weitz and R. Haag, Biomaterials, 2011, 32, 1311-1316.

14 Z. Chen, L. Zhou, F. Zhang, C. Yu and Z. Wei, Appl. Surf. Sci., 2012, 258, 5291-5298.

15 J. Khandare, A. Mohr, M. Calderón, P. Welker, K. Licha and R. Haag, Biomaterials, 2010, 31, 4268-4277.

16 M. Seiler, Fluid Phase Equilib., 2006, 241, 155-174.

17 Y. Xu, C. Gao, H. Kong, D. Yan, P. Luo, W. Li and Y. Mai, Macromolecules, 2004, 37, 6264-6267.

18 C. R. Yates and W. Hayes, Eur. Polym. J., 2004, 40, 1257-1281. 19 D. Appelhans, H. Komber, M. A. Quadir, S. Richter, S. Schwarz, J. van der Vlist, A. Aigner, M. Muller, K. Loos, J. Seidel, K. F. Arndt, R. Haag and B. Voit, Biomacromolecules, 2009, 10, 1114-1124.

20 D. Steinhilber, T. Rossow, S. Wedepohl, F. Paulus, S. Seiffert and R. Haag, Angew. Chem., Int. Ed., 2013, 52, 13538-13543. 21 G. Gasser, L. Tjioe, B. Graham, M. J. Belousoff, S. Juran, M. Walther, J.-U. Kunstler, R. Bergmann, H. Stephan and L. Spiccia, Bioconjugate Chem., 2008, 19, 719-730.

22 X. Wang and D.-S. Yang, J. Phys. Chem. A, 2006, 110, 7568-7576. 23 M. A. Quadir, Dendritic Polymers for Nanoscale Delivery of Metal Ion and Drugs (Doctoral Dissertation), Freie Universität, Berlin, 2010.

24 R. M. Rush and J. H. Yoe, Anal. Chem., 1954, 26, 1345-1347. 25 H. Kozlowski, M. Luczkowski, M. Remelli and D. Valensin, Coord. Chem. Rev., 2012, 256, 2129-2141.

26 H. Soo Choi, W. Liu, P. Misra, E. Tanaka, J. P. Zimmer, B. Itty Ipe, M. G. Bawendi and J. V. Frangioni, Nat. Biotechnol., 2007, 25, 1165-1170.

27 M. J. Knauf, D. P. Bell, P. Hirtzer, Z. P. Luo, J. D. Young and N. V. Katre, J. Biol. Chem., 1988, 263, 15064-15070.

28 P. J. Crouch, L. W. Hung, P. A. Adlard, M. Cortes, V. Lal, G. Filiz, K. A. Perez, M. Nurjono, A. Caragounis, T. Du, K. Laughton, I. Volitakis, A. I. Bush, Q. X. Li, C. L. Masters, R. Cappai, R. A. Cherny, P. S. Donnelly, A. R. White and K. J. Barnham, Proc. Natl. Acad. Sci. U. S. A., 2009, 106, 381-386. 29 W. M. Pardridge, Drug Discovery Today, 2007, 12, 54-61.

30 W. Lu, J. Wan, Z. She and X. Jiang, J. Controlled Release, 2007, 118, 38-53.

31 L. H. Reddy, R. K. Sharma, K. Chuttani, A. K. Mishra and R. R. Murthy, AAPS J., 2004, 6, e23.

32 L. Kozlovskaya and D. Stepensky, J. Controlled Release, 2013, 171, 17-23.

33 H. Petersen, P. M. Fechner, D. Fischer and T. Kissel, Macromolecules, 2002, 35, 6867-6874. 